\title{
Vídeo Digital: Colocando a Mão na Massa
}

\author{
Carmen Silvia Soares da Silva (UFRGS/CAp, carmencaca@yahoo.com.br) \\ Edson Felix dos Santos (UFRGS/CINTED, felixedson@hotmail.com) \\ Marcelo Magalhães Foohs (UFRGS/FACED, mmfoohs@gmail.com) \\ Vivian da Silva Lockmann (UFRGS/Bolsista BIC, vivilocki@yahoo.com.br)
}

\begin{abstract}
Resumo
O presente artigo é um relato de experiência de produção de vídeo digital no âmbito da temática sociedade e cidadania, ocorrida desde agosto 2009, como parte de uma pesquisa qualitativa que está sendo realizada com estudantes do segundo ano do ensino médio de uma escola pública de Porto Alegre. O objetivo geral da pesquisa é a de observar os processos de formação da cidadania através da elaboração de vídeos digitais. Outras categorias de análise envolvem o aprendizado cooperativo, o desenvolvimento de habilidades de planejamento, as habilidades técnicas relacionadas à manipulação dos equipamentos de filmagem e edição. Até o momento, podemos afirmar que as produções estão se tornando um referencial positivo na vida dos participantes em relação à utilização de novas tecnologias e da formação cidadã.
\end{abstract}

Palavras-Chaves: vídeo digital, cidadania, autoria, novas tecnologias na educação.

\begin{abstract}
This paper is about a digital video production research within the topic: society and citizenship, which has been taking place since August 2009 as part of a case study involving high school students of a public school in Porto Alegre. The general objective of this study is to observe the processes of citizenship education through digital video production. Other categories of analysis involve cooperative learning, planning skills, and editing and filming skills. Up to the moment, we can say that the productions are becoming a positive experience in the lives of the participants in relation to the use of new technology and citizenship education.
\end{abstract}

Keywords: digital video, citizenship, authorship, new technology in education.

\section{Introdução}

O presente artigo é um relato de experiência de produção de vídeo digital no âmbito da temática sociedade e cidadania, ocorrida desde agosto 2009, como parte de uma pesquisa qualitativa que está sendo realizada com estudantes do segundo ano do ensino médio de uma escola pública de Porto Alegre. O objetivo geral da pesquisa é de observar os processos de formação da cidadania através da elaboração de vídeos digitais. A produção de vídeo digital, por ser um meio eficaz de expressão de pontos de vista (Learning and Skills Development Agency, 2006), serve como instrumento de construção de um discurso multimodal (imagens, representações, linguagem falada e linguagem escrita) no qual está encerrado um mosaico de conceitos combinados de maneira original, capazes de expressar, em certos casos, o processo mesmo da formação da opinião dos autores. Através do envolvimento dos alunos em um processo de produção, há a possibilidade de se desenvolver a habilidade de argumentação, que favorece os processos de subjetivação no que se refere à identidade cidadã. A construção de vídeos digitais pode ser particularmente relevante no contexto da formação da cidadania porque permite que os estudantes reflitam sobre assuntos sociais que os afetam e desenvolvam seu pensamento em relação às implicações sociais e 
políticas dos tópicos escolhidos. A construção de um vídeo digital no âmbito da cidadania tem o potencial de instigar tal reflexão uma vez que os envolvidos nesse processo precisam pesquisar e pensar com certa profundidade sobre os tópicos de seus projetos, considerar diversos pontos de vista sobre esses tópicos e às vezes representar pontos de vista que não são necessariamente os seus. Um exemplo disso foi a dramatização executada pela turma do segundo semestre de 2009, em que os alunos assumiam diversas personalidades para recriar o choque entre traficantes e a polícia do Rio de Janeiro. A figura 1 ilustra um momento desta representação em que duas alunas assumiram o papel de mãe e de tia do policial que morreu com a queda do helicóptero abatido durante a invasão de um morro no Rio.

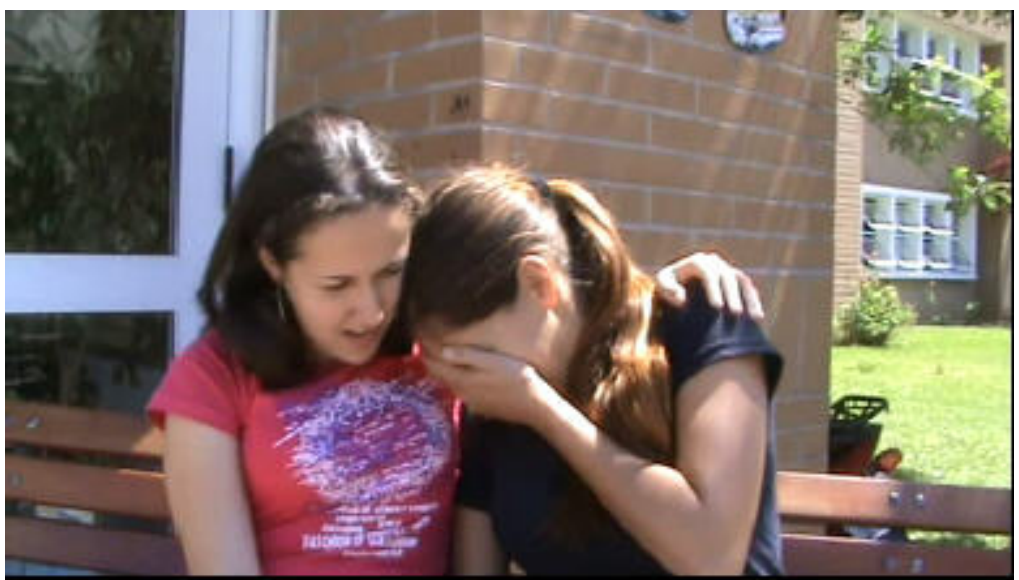

Figura 1 - Dramatização de um evento marcante atual

Por natureza, um projeto de produção de vídeo é multidisciplinar e interdisciplinar, prestando-se para uma pesquisa que utilize a análise do discurso como instrumento de interpretação do processo dialógico contido no produto final. Além disso, a produção de vídeos digitais tem o potencial de fazer com que os alunos sintam prazer de serem autores de objetos de aprendizagem, que poderão servir como auxiliares para o ensino/aprendizagem de seus colegas, aumentando assim as chances de seu engajamento com os tópicos pesquisados. Apesar de que o principal objetivo desta pesquisa é observar os processos de formação cidadã dos participantes, outras categorias de análise foram surgindo durante o desenvolvimento do estudo, são elas: (1) o aprendizado cooperativo; (2) o desenvolvimento de habilidades de planejamento, coesão e coerência de textos escritos e falados; (3) as habilidades técnicas, relacionadas à manipulação dos equipamentos de filmagem e edição.

Nossas observações têm indicado que os conceitos desenvolvidos e os processos vivenciados em um projeto de produção de vídeo digital dentro do âmbito da cidadania têm o potencial de marcar profundamente a vida dos alunos que se dediquem a ele.

\section{Fundamentação teórica}

Nesta pesquisa, o processo de produção dos vídeos digitais de cada grupo, está sendo interpretado a partir da ótica da teoria do discurso de Bakhtin (1935/1981), para a qual, as idéias contidas nos textos escritos, falados ou pictóricos são reflexo de significados sociais compartilhados, incorporados anteriormente. Interpretou-se, portanto, que as construções multimídia dos alunos (roteiros literário e técnico, encenações, trilha sonora e composição dos clipes de vídeo) são um reflexo de outros textos aos quais eles foram expostos durante suas vidas. Esse conceito, chamado de dialogismo por Bakhtin, também referido por Wertsch (1991) como dialogicidade, 
permitiu-nos especificar o contexto discursivo dos processos de composição dos vídeos digitais.

A teoria dialógica de Bakhtin descreve como significados de outros contextos e eventos (passados e presentes) manifestam-se em diálogo dinâmico com o contexto atual e modelam os processos atuais de produção de significado. Através desse filtro, pode-se observar como as produções dos estudantes estavam relacionadas com outros "fios dialógicos" (Bakhtin, 1935/1981, p. 276) que eles estavam produzindo e acessando de maneira interdisciplinar. A teoria do discurso de Bakhtin possibilitou ver como os textos que os estudantes utilizaram e produziram influenciaram, modelaram e remodelaram uns aos outros.

Para especificar como os alunos usaram os significados de eventos e contextos anteriores nos seus processos de produção de vídeo digital, lançou-se mão das teorias de intertextualidade, que estenderam a teoria do discurso de Bakhtin (1935/1981) e a noção de dialogismo (Bazerman, 2004; Fairclough, 1992; Kamberelis \& Scott, 1992). Intertextualidade refere-se à idéia de que, dentro da produção de um texto, muitos outros textos estão refletidos, citados ou referidos de alguma maneira.

Alguns estudos incorporaram explicitamente a noção de intertextualidade (Bazerman, 2004; Cairney, 1990; Callahan, 2002; Kamberelis \& Scott, 1992; Pantaleo, 2006) como arcabouço teórico para compreensão dos processos de produção em um ambiente de sala de aula. Bazerman (2004) e Cairney (1990) exploraram as maneiras pelas quais leituras prévias podem servir de intertextos nas produções dos alunos. Kamberelis e Scott (1992), por sua vez, exploraram como os alunos, utilizaram processos intertextuais na constituição de sua subjetivação e na constituição dos textos que estavam construindo.

Outros pesquisadores basearam-se explicitamente na noção de dialogismo (Dyson, 2001a, 2001b; Freedman e Delp, 2007; Ranker, 2007) em estudos de produção textual. Por exemplo, tanto Dyson (2001a, 2001b) quanto Ranker (2007) exploraram as maneiras em que os estudantes podem combinar textos de várias mídias em um único texto que retém um relacionamento dialógico com os textos das diversas mídias que foram utilizados para produzi-lo.

Nesta pesquisa, o filtro dialógico-intertextual foi ampliado com elementos da teoria semiótica social (Hodge \& Kress, 1988; Kress, 1997, 2001; Van Leeuwen, 2004) incluindo o conceito de que textos são multimodais (Kress, 2000, 2003), situados em contextos sociais específicos e produzidos através de recursos semióticos, a partir dos quais os indivíduos constroem significados de acordo com os propósitos de suas produções. A teoria semiótica social amplia e desenvolve os conceitos da teoria semiótica (Barthes, 1967; de Saussure, 1916/1974) inserindo-os em um contexto discursivo e social, necessário para a percepção dos processos de construção do sujeito cidadão pelos alunos participantes deste estudo.

A partir de uma perspectiva semiótica social, os processos de produção de significado usam vários "recursos semióticos” que estão disponíveis dentro de um contexto social em um processo contínuo de produção e comunicação de significados, denominado de semiose. A noção de recurso semiótico refere-se a um significado potencial (Halliday, 1978) ou signo, na semiótica tradicional. Van Leeuwen (2004) observou que "na semiótica social o termo recurso é preferido porque evita a impressão de que o signo é pré-estabelecido e não é afetado pelo seu uso. A partir da perspectiva da semiótica social, semiose é um processo contínuo de seleção e combinação de recursos semióticos de acordo com a situação social que é enfatizada pelos textos. Em outras palavras, "o processo de semiose fica estampado momentaneamente sob forma textual (Kress, 2001, p. 141). À luz desse conceito, os discursos multimodais dos alunos 
deste estudo são montagens de outros elementos textuais ou recursos semióticos, combinados em um todo coerente que tem o potencial de revelar aspectos do processo da formação cidadã.

Alguns pesquisadores incorporaram um arcabouço semiótico ao estudar os processos de composição dos alunos em conjunção com a escrita em ambiente de sala de aula (Cowan \& Albers, 2006; Harste, Woodward, \& Burke, 1984; Labbo, 1996). Contudo, poucos estudos incorporaram explicitamente um arcabouço teórico semiótico social. O estudo de Mavers (2007) sobre a produção de significados de uma criança (usando os recursos de correspondência eletrônica em conversação com seu tio) aproxima-se do campo da semiótica social na explicação de como esse relacionamento e propósito comunicativo deu forma ao uso, pela criança, dos recursos semióticos de correspondências eletrônicas. Em um estudo de base no desenvolvimento da semiótica social, Kress (1997) estudou a maneira com que produtores de sinais são guiados a lançar mão de recursos semióticos de acordo com seus interesses e propósitos comunicativos, combinando-os de tal modo que satisfaz esse interesse e propósito.

As novas categorias de análise que foram surgindo durante o desenvolvimento deste estudo, que são: (1) o aprendizado cooperativo; (2) o desenvolvimento de habilidades de planejamento, coesão e coerência de textos escritos e falados; (3) as habilidades técnicas, relacionadas à manipulação dos equipamentos de filmagem e edição, estão sendo interpretadas à luz dos conceitos desenvolvidos por Vygotsky (1979), que acreditava que a atividade externa deveria ser considerada como processos sociais mediatizados semioticamente. Também, argumentava que as propriedades desses processos proporcionariam a chave para entender a aparição do funcionamento interno. Para Vygotsky, a internalização é “a reconstrução interna de uma operação externa” (Vygotsky, 1979, p.92). O exemplo dado pelo autor para explicar o processo de internalização, é o ato de assinalar. Inicialmente, para o aprendiz, esta ação é um ato falido de alcançar algum objeto, um movimento dirigido a alcançar algo. Quando outra pessoa chega perto desse aprendiz, interpreta esse movimento como assinalamento. Portanto, para o aprendiz que inicialmente significava alcançar um objeto, após interagir com uma pessoa e constatar que ela interpreta esse movimento como assinalamento, o aprendiz acaba internalizando essa ação. Com base nessas idéias, Vygotsky criou a "Lei da dupla formação", que consiste no fato que:

“... toda função aparece duas vezes: primeiro, em nível social e mais tarde em nível individual; primeiro entre pessoa (interpessoal) e mais tarde, individual, no interior do próprio sujeito (nível intrapsicológico). Isso pode aplicar-se igualmente à atenção voluntária, à memória lógica e à formação de conceitos. Todas as funções superiores originam-se como sendo relações entre seres humanos” (Vygotsky, 1979, p.94).

Portanto, estamos observando as novas categorias de análise que surgiram à luz da reconstrução individual de uma atividade externa e social. Ou seja, estamos procurando a gênese dos processos de desenvolvimento individual de tais categorias, no envolvimento social dos indivíduos participantes do estudo entre si, com os professores e com outras pessoas alheias ao estudo.

\section{Abordagem metodológica}

Este estudo está sendo desenvolvido com alunos do segundo ano do ensino médio de uma escola pública de Porto Alegre. No decorrer do segundo semestre de 2009 (com nove participantes) e primeiro semestre de 2010 (com doze participantes) foram 
executados dois cursos de extensão de técnicas de produção de vídeo digital no âmbito da temática sociedade e cidadania. Durante esses cursos, observamos diretamente a atuação dos alunos em sala de aula, filmamos diversos momentos do processo de produção dos vídeos digitais e recolhemos material escrito e desenhado correspondentes aos roteiros e storyboards, respectivamente.

Na construção de seus projetos de video, os alunos envolveram-se na elaboração de um roteiro, na reflexão sobre um tema e na filmagem e edição de um video. Os alunos participantes foram divididos em grupos conforme os tópicos de interesse de cada um. Cada grupo sugeriu um tema sobre a cidadania a ser trabalhado, a partir do qual foi pesquisado o conteúdo e formulado um roteiro para posterior filmagem e produção de vídeo. O processo de produção foi trabalhado em três etapas:

Etapa 1- Fase de pré- produção do vídeo. A etapa de pré-produção foi desenvolvida no laboratório de informática com a orientação dos professores responsáveis pela disciplina e auxílio de um editor de textos, do software PowerPoint e programas de edição de video. A pré-produção compreende a elaboração do roteiro (Argumento, Roteiro Literário, Roteiro Técnico e storyboard), a análise técnica e a elaboração do cronograma. Atividades relacionadas a essa fase:

1. Formação dos grupos de alunos.

2. Apresentação e discussão de temas sobre sociedade.

3. Definição dos temas, estudo de aprofundamento e planejamento.

4. Oficina de edição de vídeos com KdenLive.

5. Oficina de edição de vídeos com Movie Maker

6. Roteiro Técnico: desconstrução de um comercial.

7. Criação do roteiro (produto escrito).

8. Construção do storyboard.

9. Técnicas de dramatização.

Etapa 2- Fase de produção. Nessa fase ocorreram as filmagens e visitas a campo. A etapa de produção envolveu estratégias delineadas na fase de planejamento. Dependendo do planejamento ocorreram visitas de campo, entrevistas, dramatizações e outros recursos midiáticos necessários para levar a bom termo a intenção comunicativa dos autores. As filmagens foram realizadas por um dos professores, seguindo a orientação dos alunos-autores. Os grupos de alunos foram acompanhados aos locais previstos pelo programa de visitas do projeto de extensão conforme os temas de cidadania escolhidos por eles. Foi realizada no segundo semestre de 2009 uma visita à usina de triagem de lixo da Vila Pinto no bairro Bom Jesus, onde os alunos tomaram conhecimento dos mecanismos da triagem e das estruturas da usina. Foram realizadas entrevistas com as trabalhadoras. As entrevistas registradas em video, foram posteriormente utilizadas pelos alunos em seus projetos. A figura 2 ilustra um dos momentos dessa visita. 


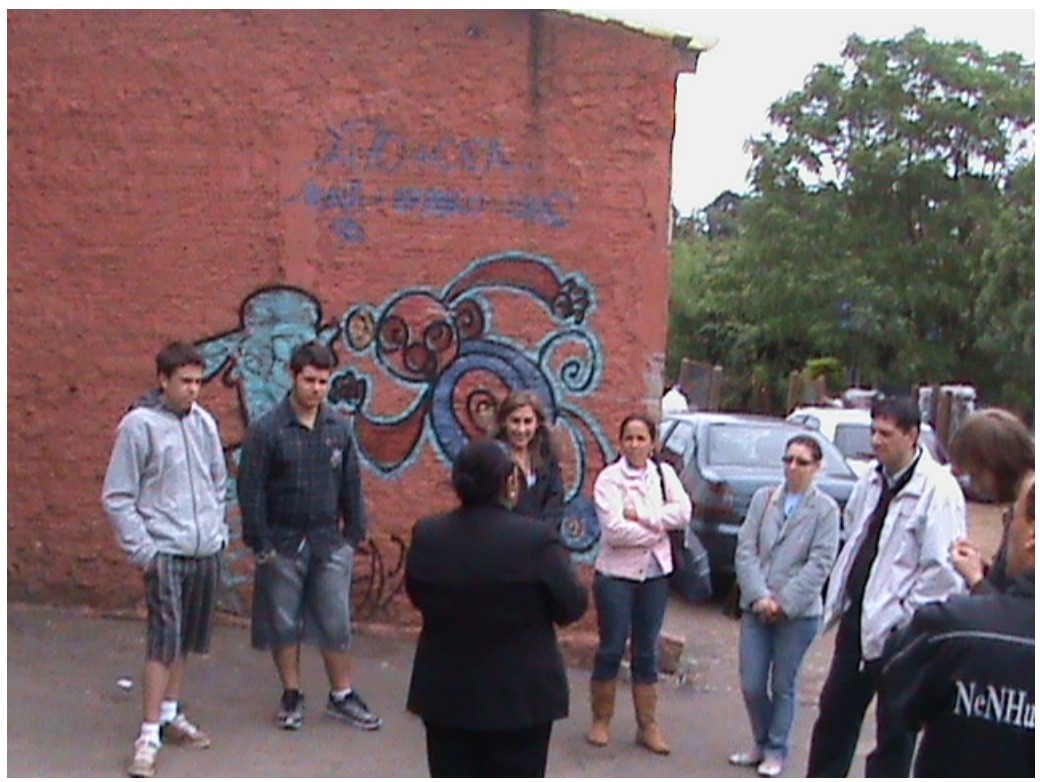

Figura 2 - Visita à usina de triagem Vila Pinto

No atual semestre (2010/1) estão programadas visitas em locais especificos (Abrigo do bairro Bom Jesus, Administração do Trensurb e Usina do Gasômetro) onde ocorrerão entrevistas e/ou coletas de imagem (videos).

Etapa 3- Fase de pós-produção: edição do material gravado e publicação. A fase de pós-produção foi realizada no laboratório de informática com o auxílio do software de edição de vídeos Movie Maker. Os alunos apropriaram-se da novas tecnologias através da utilização da mesma, ou seja, colocando a mão na massa.

Os dados foram coletados através de questionários, entrevistas individuais e em grupo, observação sistemática direta do comportamento dos alunos em ação e das produções referentes a cada etapa. Para análise dos dados estão sendo utilizados os pressupostos teóricos abordados no item Fundamentação Teórica deste artigo. Até o presente momento, podemos observar que houve uma intensa interação entre os membros dos grupos entre si e com os professores em todas as etapas de produção. Chama a atenção o fato de que os alunos construíram seus roteiros em ciclos de aperfeiçoamento em que os membros debatiam exaustivamente o planejamento dos diálogos, cenários e planos de filmagem. A dinâmica dos debates é rápida e muitas vezes bastante barulhenta. Há um controle interno de respeito mútuo observando-se um limite de liberdades, a partir do qual o grupo reage e serve como regulador. Os produtos finais evidenciam a montagem de conceitos veiculados por diversas mídias, especialmente a televisão. A figura 3 ilustra a influência direta de programas eleitorais veiculados pela televisão na formação de conceitos relacionados à política.

No roteiro referente a esta cena, os autores tratam de maneira irônica as promessas de campanha que nunca se realizam. O Partido pela Mudança, criado pelo grupo, promete mudanças na saúde, na economia e na educação, que são impossíveis de serem realizadas, demonstrando uma percepção pouco favorável com relação à classe política além de um ceticismo quanto aos seus discursos. 


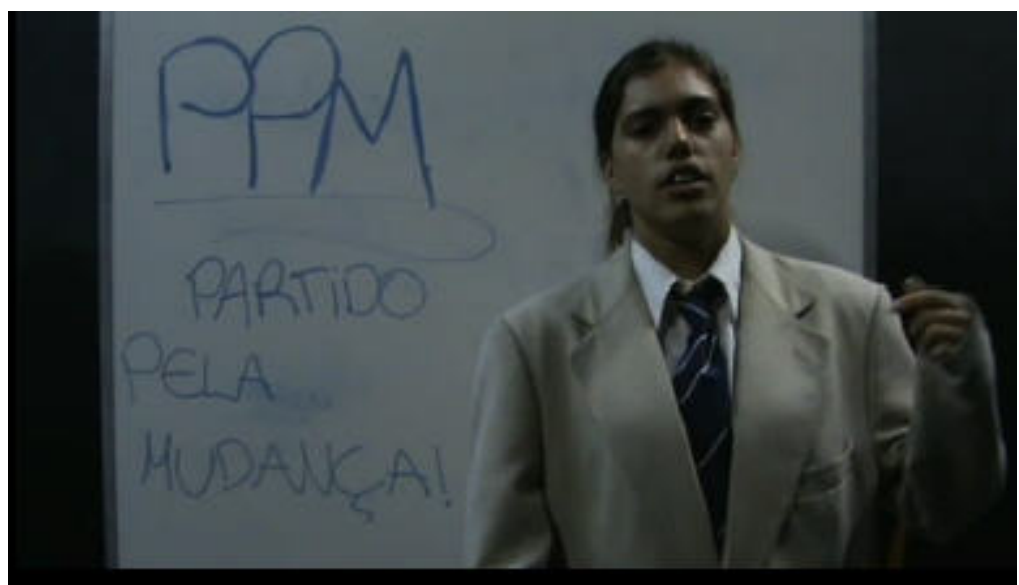

Figura 3 - Influência da mídia televisão na formação cidadã

Nas produções dos alunos está presente também a opinião de pais e professores. Isso foi possível identificar através de entrevistas com os membros dos grupos sobre a origem das idéias veiculadas em seus vídeos. O mosaico de conceitos, em todas as produções, foi elaborado com o claro intuito de influenciar a opinião alheia. Pelos dados coletados, consegue-se traçar uma trajetória desde a idéia original até o produto final, passando pelas fases de amadurecimento das opiniões e das técnicas planejadas para influenciar o publico que irá assistir ao vídeo.

\section{Considerações finais}

Ainda faltam dois cursos, que estão programados para o segundo semestre de 2010 e primeiro semestre de 2011. Até o momento, podemos afirmar que as produções estão se tornando um referencial positivo na vida dos participantes em relação à utilização de novas tecnologias e da formação de opinião sobre questões relacionadas à cidadania.

Concluímos, até o momento, que o processo de produção de vídeo digital, quando utilizado em atividades de ensino, pode trazer vários benefícios aos participantes. Benefícios como, por exemplo: desenvolvimento do pensamento critico, promoção da expressão e da comunicação, favorecimento de uma visão interdisciplinar, integração de diferentes capacidades e inteligências e valorização do trabalho em grupo.

\section{Referências bibliográficas}

Bakhtin, M. M. (1981). Discourse in the novel (C. Emerson \& M. Holquist, Trans.). In M. Holquist (Ed.), The dialogic imagination (pp. 259-422). Austin: University of Texas Press. (Original work published in 1935)

Bangert-Drowns, R. (1993). The word processor as an instructional tool: A metaanalysis of word processing in writing instruction. Review of Educational Research, 63(1), 69-93.

Barthes, R. (1967). Elements of semiology. London: Cape.

Barton, D., \& Hamilton, M. (2000). Literacy practices. In D. Barton, M. Hamilton, \& R. Ivanic (Eds.), Situated literacies (pp. 7-15). New York: Routledge. 
Bazerman, C. (2004). Intertextualities: Volosinov, Bakhtin, literary theory, and literacy studies.In A. Ball \& S. Freedman (Eds.), Bakhtinian perspectives on language, literacy, and learning (pp. 53-65). Cambridge, UK: Cambridge University Press.

Block, L., \& Rydin, I. (2006). Digital rapping in media productions: Intercultural communicationthrough youth culture. In D. Buckingham \& R. Willett (Eds.), Digital generations: Children,young people, and new media (pp. 295-312). Mahwah, NJ: Lawrence Erlbaum.

Burn, A., \& Parker, D. (2003). Tiger's big plan: Multimodality and the moving image. In C. Jewitt \& G. Kress (Eds.), Multimodal literacy (pp. 56-72). New York: Peter Lang.

Cairney, T. (1990). Intertextuality: Infectious echoes from the past. Reading Teacher, 43(7), 478-484.Crítica, 1979.

de Saussure, F. (1974). Course in general linguistics. London: Peter Owen. (Original work published in 1916)

Dowdy, J., Reedus, N., Anderson-Thompkins, S., \& Heim, P. (2003). The making of griots:One Black filmmaker’s journey with six teenagers. High School Journal, 86(4), 49-62.

Downes, E., \& McMillan, S. (2000). Defining interactivity. New Media and Society, 2(2), 157-179.

Freedman, S., \& Delp, V. (2007). Conceptualizing a whole-class learning space: A grand dialogic zone. Research in the Teaching of English, 41(3), 259-268.

Kress, G. (1997). Before writing: Rethinking paths to literacy. New York: Routledge.

Kress, G. (2000). Multimodality. In B. Cope \& M. Kalantzis (Eds.), Multiliteracies: Literacy learning and the design of social futures (pp. 182-202). New York: Routledge.

Kress, G. (2001). Text as the punctuation of semiosis: Pulling at some of the threads. In U. Meinhof \& J. Smith (Eds.), Intertextuality and the media: From genre to everyday life (pp. 132-154). Manchester, UK: Manchester University Press.

Kress, G. (2003). Literacy in the new media age. London: Routledge.

New London Group. (2000). A pedagogy of multiliteracies: Designing social futures. In B. Cope \& M. Kalantzis, (Eds.), Multiliteracies: Literacy learning and the design of social futures (pp. 9-37). New York: Routledge.

Vygotsky, Lev. A formação social da mente. São Paulo: Martins Fontes, 1989.

Vygotsky, Lev. EI desarrollo de los procesos psicológicos superiores. Barcelona: 1989.

Vygotsky,, Lev. Pensamento e Linguagem. São Paulo: Martins Fontes, 1987. 